\title{
A ROTARY TUNER FOR UHF DRIFT-TUBE LINACS*
}

\author{
D. J. Liska, H. Mignardot, G. W. Zimmerman, and J. H. Billen
}

MS -H821, Los Alamos National Laboratory, Los Alamos, NM 87545

\begin{abstract}
A rotary tuner has been developed and tested in a $425-\mathrm{MHz}$ ramped gradient drift-tube linac and also in a $350-\mathrm{MHz}$ DTL cold model tank. This type of tuner utilizes a rotary paddle to displace the magnetic field at the tank wall to vary the inductance and resonant frequency of the drifttube linac. The tuning paddle effective area is about $7 \%$ of the cross-sectional area of the DTL tank and shifts the resonant frequency by about $350 \mathrm{kHz}$ for $90^{\circ}$ of rotation. Advantages of the tuner include low friction for fast and accurate response, no $\mathrm{RF}$ seals, low wall currents at the shaft feedthrough, and minimal cutout volume at the tank wall. The small cutout volume is important in applications in which tank wall cooling is critical. A smaller heliumcooled version of this device is being developed for use in $850-\mathrm{MHz}$, cryogenically cooled drift-tube linacs.
\end{abstract}

\section{Description of the Rotary Tuner}

A water-cooled version of the rotary tuner is shown in Fig. 1. This device was developed for the 425-MHz ramped

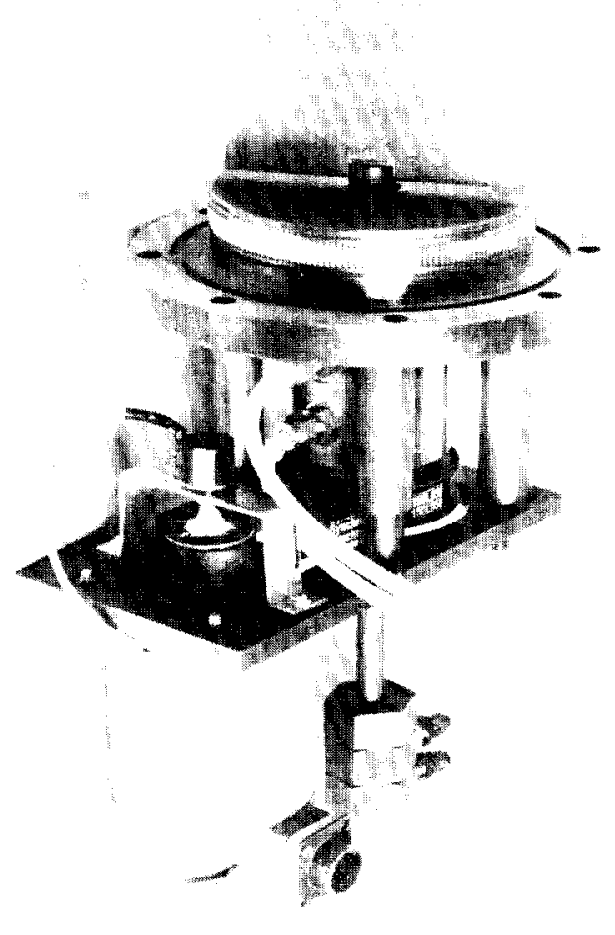

Fig. 1. Water-cooled $425-\mathrm{MHz}$ rotary tuner.

\footnotetext{
*Work performed under the auspices of the U.S. Department of Energy, Office of Fusion Energy and sponsored in part by the U.S. Army Strategic Defense Command.
}

gradient drift-tube linac (RGDTL). The paddle is $12.7 \times$ $7.6 \times 0.7 \mathrm{~cm}$ thick and cooled using $0.32-\mathrm{cm}$ refrigerator tubing soldered between two copper sheets. The drive shaft is $0.95 \mathrm{~cm} \mathrm{OD}$, double-walled copper tubing. The rotary tuner was developed experimentally to replace an existing slug tuner so the drive shaft feeds through a thick copper adapter flange designed to fit the original slug tuner port. The shaft is vacuum sealed with a Ferrofluidic bearing and is belt driven with a stepper motor. The paddle can be overdriven because the tuning effect is approximately sinusoidal and repetitive. Thus, unlike a slug tuner, no limit switches are required. In normal operation, the tuner is driven to maintain the DTL resonance close enough to the drive frequency so that VSWR limits are not exceeded.

A cryogenically cooled version of a rotary tuner has been designed for an 850-MHz DTL and is shown in Fig. 2.
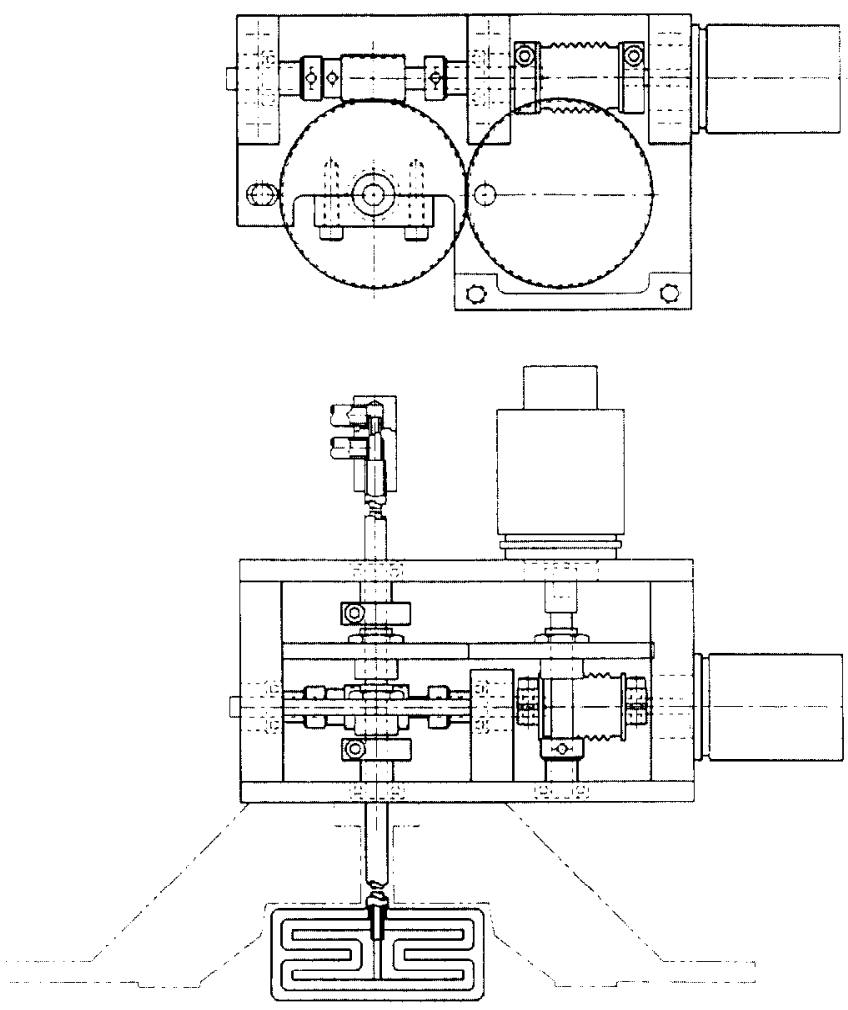

Fig. 2. Cryogenic $850-\mathrm{MHz}$ rotary tuner

This unit is gear driven using stainless steel worm and spur gears. The copper paddle is only $6.4 \times 2.5 \times 0.5 \mathrm{~cm}$ thick and is cooled with 15 atm of helium gas at $23 \mathrm{~K}$. The drive shaft is $0.64-\mathrm{cm}$ OD stainless steel. The bearings are cryogenically rated as is the stepping motor. This unit "plugs" into the DTL tank through a longitudinal keyhole slot slightly longer than the paddle. This allows the gundrilled cooling passages in the tank to be unimpeded in contrast with a typical slug tuner porthole in which cooling around the porthole can be problematic. 


\section{Test Results}

The water-cooled rotary tuner prototype has been tested in the 1.8-m-long, 425-MHz RGDTL at low power. The unit was installed at the high-power (downstream) end of the ramped structure. At full power, this end of the DTL develops an accelerating gradient of $4.4 \mathrm{MV} / \mathrm{m}$. Figure 3

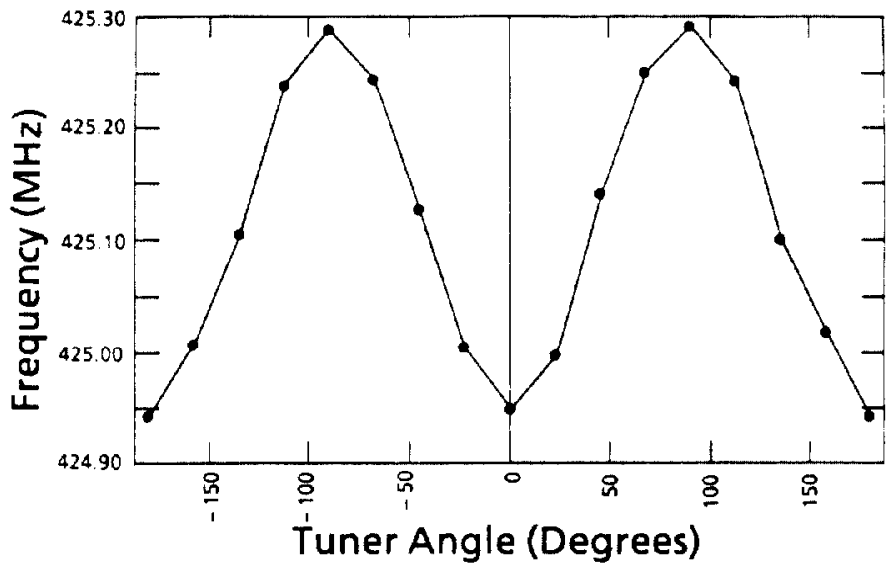

Fig. 3. Cavity frequency vs tuner angle for the rotary tuner installed in the ramped gradient drift-tune linac. Zero and $\pm 180^{\circ}$ correspond to the tuner aligned with the $\mathrm{TM}_{010}$ field for the minimum field distortion. Tuning range is about $350 \mathrm{kHz}$

shows a low-power measurement of the cavity frequency vs the tuner orientation angle. An angle of $0^{\circ}$ corresponds to the flat plane of the paddle aligned parallel to the azimuthal $\mathrm{TM}_{010}$ magnetic field. At this orientation, the "insertion" perturbation is minimum at $+64 \mathrm{kHz}$. That is, the frequency of the cavity is raised by $64 \mathrm{kHz}$. At any other orientation angle, the paddle displaces a larger volume of magnetic field than the actual volume of the paddle. This is due to the large aspect ratio of the paddle (18.4:1). The maximum frequency perturbation of $+414 \mathrm{kHz}$ occurs at $\pm 90^{\circ}$, equivalent to a gain of about 6.5 over the actual paddle volume. The effective tuning range is the difference of the maximum and insertion perturbations, or $350 \mathrm{kHz}$.

Because the insertion perturbation varies directly as the edge-on area of the paddle, whereas the maximum perturbation is due to the face-on area, doubling the thickness of the paddle $(1.4 \mathrm{~cm})$ will increase the insertion perturbation at $0^{\circ}$ to about $+128 \mathrm{kHz}$. Thus, the tuning range of the rotary tuner would be reduced from $350 \mathrm{kHz}$ to about $286 \mathrm{kHz}$. It is advantageous, therefore, to make the paddle as thin as possible.

\section{Axial Field Perturbation Caused by Paddle}

Further tests were performed in a cold-model $350-\mathrm{MHz}$ DTL cavity equipped with post couplers. The relative size and shape of the tuner paddle mockup tested was similar to the operational model tested at $425 \mathrm{MHz}$ in the RGDTL. The $350-\mathrm{MHz}$ tests concentrated on the axial field distribution in the cavity for various angles of the rotary tuner $\left(0^{\circ}, 45^{\circ}, 90^{\circ}\right)$ compared to the fields with no tuner in place. At these angles, the maximum field perturbations were $1 \%, 1.7 \%$, and $3.1 \%$, respectively, with the tuner affecting the nearest four or five DTL cells. These errors can be mitigated in actual applications because the post couplers can be adjusted for the proper field distribution with the tuner installed and set to an intermediate position. If this is done, then the maximum field differences can be reduced to less than $2 \%$ over the full range of the tuner.

\section{Conclusions}

Preliminary low-power tests of a water-cooled version of a rotary tuner have been successfully completed in a 425 $\mathrm{MHz}$ RGDTL. Additional field distribution tests were performed in a $350-\mathrm{MHz}$ DTL cold model. High-power tests will be conducted shortly. Also, a cryogenic version of the rotary tuner for use in a helium-cooled $850-\mathrm{MHz}$ DTL has been designed and will be tested soon. From the tests completed so far, it appears feasible to achieve several hundred kilohertz of tuning range with under $2 \%$ perturbation to the axial field distribution in a DTL.

The rotary tuner combines certain advantages over a conventional slug tuner. Insertion of the paddle through a keyway slot poses less interruption of longitudinal cooling passages in the tank wall. Because of the small drive shaft, the coupling into resonant back volumes as sometimes happens in slug tuner assemblies with accompanying bellows failure problems is virtually eliminated as is the need for RF seals. There is very low friction, thus permitting fast accurate control in the manner of a linear servomechanism. Finally, the bulk, size, and expense of the rotary tuner is less than that of a slug tuner; therefore, the mechanism is considerably simpler to design and fabricate.

\section{References}

1. "A High Intensity Drift-Tube Linac with Ramped Accelerating Gradient," D.J. Liska, H. Mignardot, J. H. Billen, L. B. Dauelsberg, and G. W. Zimmerman, 1988 Linac Conference, Williamsburg, VA, to be published

2. A Drift-Tube Linac Incorporating a Ramped Accelerating Field, D. J. Liska, L. B. Dauelsberg, 1987 IEEE Particle Accelerator Conference, IEEE Catalog No. 87CH2387-9, p. 1797. 